\title{
Maternal perceptions of children's weight status
}

\author{
L. Lopes, ${ }^{\star}$ R. Santos, $\uparrow$ B. Pereira ${ }^{\star}$ and V. Lopes $\ddagger$ \\ ${ }^{*}$ Research Centre on Child Studies (CIEC), Institute of Education, University of Minho, Braga, Portugal \\ $\dagger$ Research Centre for Physical Activity, Health and Leisure (CIAFEL), Faculty of Sports Science, University of Porto, Porto, Portugal \\ $\ddagger$ Research Center in Sports Sciences, Health Sciences and Human Development (CIDESD), Department of Sports Science of \\ Polytechnic Institute of Bragança, Bragança, Portugal
}

Accepted for publication 28 January 2012

\author{
Keywords \\ children, parental \\ perceptions, weight \\ status \\ Correspondence: \\ Luís Lopes, Institute of \\ Education, University of \\ Minho, Campus de \\ Gualtar, 4710-057 Braga, \\ Portugal \\ E-mail: \\ luis.iec.um@hotmail.com
}

\begin{abstract}
Background Several studies have addressed mothers' perceptions of their children's weight status; however, there is no investigation on Portuguese children (a country with one of the highest levels of children's overweight and obesity in Europe). The aim of this study was to quantify maternal misclassification of child weight status in a sample of Portuguese children aged 9 to 12 years, according to gender, family income, and maternal weight status, education level and age.

Methods Data were collected in a school-based study (school year 2009/2010) in northern Portugal with 499 urban children (236 girls; 47.3\%). Body mass index was calculated from measurements of height and weight [body mass $(\mathrm{kg}) /$ height $\left(\mathrm{m}^{2}\right)$ ]. Mothers' perceptions of child's weight status, age, height and weight were accessed by a questionnaire. Children's age, gender and socio-economic status were extracted from the schools' administrative record systems. Cohen's Kappa was used to analyse the misperceptions and the agreement between children's objectively measured weight status and mothers' perception of their child's weight status.

Results The prevalence of underweight, overweight and obesity in children was $4.6 \%, 25.5 \%$ and $6.4 \%$, respectively. A proportion of $65.2 \%$ of underweight and $61.6 \%$ of overweight/obese children were misclassified by their mothers. For the majority of variables presented, the values of agreement were fair ( $k$ ranged from 0.257 to 0.486 ), but were statistically significant. Significant differences in the percentages of mothers who correctly classified their children's weight status were only found among the most educated in the overweight/obese group and among the normal-weight mothers in the underweight group.

Conclusions Many mothers do not properly recognize their children's weight status and frequently underestimate their children's body size.
\end{abstract}

\section{Introduction}

Parental acknowledgement of a child's excess weight and an understanding of its health consequences are crucial primary steps in tackling obesity (Jeffery et al. 2005). However, parents often do not accurately perceive their children's weight status, report low levels of concern and are not aware of the health risks associated with excess fat accumulation (Baughcum et al. 2000; Wake et al. 2002; Maynard et al. 2003; Carnell et al. 2005; Jeffery et al. 2005; Eckstein et al. 2006).

Literature on parental perceptions of children's weight status reports high rates of parental misperceptions (Maynard et al. 2003; Eckstein et al. 2006) and indicates that mothers are more likely than fathers to correctly assess their child's weight (Jeffery 
et al.2005). It also states that older children are more likely to be accurately classified than younger ones (Maynard et al. 2003; Campbell et al. 2006). Results for socio-economic status, race/ ethnicity and gender are contradictory (Baughcum et al. 2000; Maynard et al. 2003; Carnell et al. 2005; Jeffery et al. 2005; West et al. 2008). However, most of the research in this field has been carried out in the USA, Australia and the UK; consequently, studies in other populations with different social and cultural backgrounds are necessary in order to understand if the associations found in those countries can be generalized.

In Portugal, about one-third of children and adolescents are overweight or obese (Sardinha et al. 2011), which emphasizes the need for a large variety of strategies to fight this epidemic. Knowing how Portuguese mothers view their children's weight status is an important step for intervention programmes.

The aim of this study was to quantify maternal misclassification of child weight status in a sample of Portuguese children aged 9 to 12 years, according to gender, family income, and maternal weight status, education level and age.

\section{Methods}

\section{Study design and sampling}

Data for the present study were derived from the Bracara Study aimed to evaluate the relations between Motor Coordination, Physical Activity, Physical Fitness, Body Composition, Academic Achievement and Health Behaviours among elementary school children. The Bracara Study was conducted in a middle city located in the north of Portugal during the 2009/2010 academic year (September to June).

All 21 public elementary schools in the city that qualified as urban (according to the Municipal Administration Registry) were considered and invited to participate in this study, corresponding to 846 children enrolling in the fourth grade. Two schools, totalling 90 children, decided not to take part in this study; six schools ( 130 children) could not be evaluated on time to take part in this study; 127 children had missing information on the variables of interest or failed the inclusion criteria (because of a mental and/or physical disability or a health condition that did not allow them to participate in physical education classes) - all were excluded from this analysis. Therefore, the study included 13 urban public elementary schools and 499 participants (236 girls; 47.3\%), aged 9-12 years old.

The schools' directors and the children's parents/guardians received a verbal and written description of the study and signed a written informed consent form. The employed protocol and procedures followed the Helsinki Declaration for
Investigation in Human Subjects and were approved by the Curricular Development and Innovation Division (Portuguese Ministry of Education) and by the University's Ethics Committee.

\section{Measures}

\section{Children's weight status}

Stature and body mass were measured using a stadiometer (Seca 220) and a scale (Tanita TBF-300) according to standardized procedures in light indoor clothing, without shoes. Values were recorded to the nearest $0.1 \mathrm{~cm}$ and $100 \mathrm{~g}$, respectively. Body mass index (BMI) was calculated as body weight (kg), divided by height $(\mathrm{m})$, squared. Weight status was determined according to the International Obesity Task Force (Cole et al. 2000, 2007) cut-offs for BMI: underweight, normal weight, overweight and obese. The overweight and obese categories were combined. Data were collected during regularly scheduled physical education classes by a team of specialized examiners and with the help of physical education teachers.

\section{Maternal perceptions of weight status}

A questionnaire was distributed to parents for assessing general child and parental health variables, divided in three sections: the first section collected information related to the child; the second section was related to parental characterization; the third section addressed parental physical activity. For this study, only the mothers' perceptions of their child's weight status and the mothers' self-reported height and weight were used. The mother's appraisal of her child's weight was assessed with the question: 'How would you describe your child's weight at the moment? (underweight, normal weight, overweight or obese)'. A total of 596 questionnaires were sent out and 499 were returned (83.7\% response rate). Dropout analysis showed that the missing $16.3 \%$ of children had a BMI that was not different from that of those included (mean BMI for excluded $19.01 \pm 3.86$ vs. mean BMI for included $18.50 \pm 3.10$, $P=0.122)$.

\section{Mother's weight status}

The mothers' height and weight were assessed by the above mentioned questionnaire and BMI was then calculated and defined according to the World Health Organization (2000) cut-off points. 


\section{Sociodemographic measures}

Each child's family income was extracted from the schools' administrative record systems. The school's family income used by the Portuguese Ministry of Education is based on annual family income (eligible for benefit A, benefit B, or not eligible) and was used as a proxy measurement of family socio-economic status (Portuguese Ministry of Education 2009). The questionnaire also included a question about mothers' education level and was also used as a measure of socio-economic status. Mothers were categorized according to the Portuguese Education Level: Low (mandatory education - 9 school years), Medium (secondary education - 12 school years) and High (college or university degree).

\section{Statistical analysis}

For the family income and for the mothers' weight status variables, because of the small size of participants eligible for benefits $A$ and $B$ and of those in the overweight and obese categories respectively, the participants were grouped. Therefore, for the family income status analysis two groups were considered: those with school social benefits and those without. For the mothers' weight status two groups were considered: normal weight and overweight/obese. Mothers' ages were divided into two groups by the median value: $\leq 39$ years old and $\geq 40$ years old.

An analysis of variance (ANOVA) with Scheffé post-hoc test for multiple comparisons was performed in order to test the differences between groups for continuous variables. Crosstabulation examined unadjusted bivariate associations between child weight status categories and family income, gender, mother's weight status, age and education level, with chi-squared test or with Fisher's exact test. Cohen's Kappa test was used to assess the inter-rater agreement between the percentages of participants in each of the weight status categories (underweight, normal weight, overweight/obese). The Cohen's Kappa value can be interpreted by the strength of agreement: $k<0.20$ poor; $0.21<k<0.40$ fair; $0.41<k<0.60$ moderate; $0.61<k<0.80$ good; $0.81<k<0.100$ very good (Altman 1991).

All statistical analyses were performed using PAsw Statistics 19 (Statistical Program for Windows). The level of significance for all analyses was set at 0.05 .

\section{Results}

The prevalence of underweight, overweight and obese children was $4.6 \%, 25.5 \%$ and $6.4 \%$, respectively. In girls, 5.9\% were underweight, $27.1 \%$ were overweight, and $5.9 \%$ were obese; corresponding figures for boys were $3.4 \%, 24 \%$ and $6.8 \%$, respectively.

Descriptive statistics for the age, weight, height and BMI of the child and mother by child weight status are summarized in Table 1. Mothers of the overweight/obese children were heavier and had a higher BMI than mothers of normal-weight children $(P<0.001$ and $P=0.03$ respectively).

Mothers' perceptions of their child's weight status are presented in Table 2; the percentage of the total agreement between the child's objectively measured weight status and mother's perception of the child's weight is $71.1 \%$. The normal-weight category contributed more at a total agreement of $57.3 \%$, followed by the overweight/obese category with $12.2 \%$. A pro-
Table 1. Child and mother characteristics by child weight status (mean and standard deviation)

\begin{tabular}{|c|c|c|c|c|}
\hline & \multicolumn{3}{|c|}{ Child weight status } & \multirow[b]{2}{*}{ ANOVA } \\
\hline & $\begin{array}{l}\text { Underweight } \\
n=23(4.6 \%) \\
\text { Mean (SD) }\end{array}$ & $\begin{array}{l}\text { Normal weight } \\
n=317(63.5 \%) \\
\text { Mean (SD) }\end{array}$ & $\begin{array}{l}\text { Overweight/obese } \\
n=159(31.9 \%) \\
\text { Mean (SD) }\end{array}$ & \\
\hline \multicolumn{5}{|l|}{ Child } \\
\hline Age & $9.74(0.67)$ & $9.55(0.53)$ & $9.61(0.46)$ & $F(2,496)=2.07 ; P=0.127$ \\
\hline Weight & $26.27(3.10)^{*} \dagger$ & $31.94(4.55) \dagger$ & $44.64(7.05)$ & $F(2,496)=327.13 ; P<0.001$ \\
\hline Height & $1.37(0.09) \dagger$ & $1.37(0.07) \dagger$ & $1.41(0.06)$ & $F(2,496)=24.89 ; P<0.001$ \\
\hline BMI $\left(\mathrm{kg} / \mathrm{m}^{2}\right)$ & $13.99(0.75)^{*} \dagger$ & $17.03(1.41) \dagger$ & $22.31(2.41)$ & $F(2,496)=549.10 ; P<0.001$ \\
\hline \multicolumn{5}{|l|}{ Mother } \\
\hline Age & $39.65(4.73)$ & $38.58(5.53)$ & $38.58(6.35)$ & $F(2,492)=0.388 ; P=0.685$ \\
\hline Weight & $61.66(10.57)$ & $63.06(10.31) \dagger$ & $67.49(9.80)$ & $F(2,459)=9.85 ; P<0.001$ \\
\hline Height & $1.62(0.06)$ & $1.61(0.07)$ & $1.62(0.07)$ & $F(2,457)=1.97 ; P=0.141$ \\
\hline BMI $\left(\mathrm{kg} / \mathrm{m}^{2}\right)$ & $23.39(4.36)$ & $24.43(3.79) \dagger$ & $25.64(3.70)$ & $F(2,445)=5.96 ; P=0.03$ \\
\hline
\end{tabular}

*Significantly different from the normal weight group $(P<0.05)$. †Significantly different from the overweight/obese group $(P<0.05)$. BMI, body mass index. 
Table 2. Percentages and Cohen's Kappa values of agreement between mother's perceptions of child weight status and objectively measured child weight status for total sample and by family income and gender

\begin{tabular}{|c|c|c|c|c|c|}
\hline \multirow{2}{*}{$\begin{array}{l}\text { Maternal perception of } \\
\text { child's weight status }\end{array}$} & \multicolumn{3}{|c|}{ Child weight status } & \multirow{2}{*}{$\begin{array}{l}\text { Cohen's Kappa coefficient } \\
\text { (\% total agreement) }\end{array}$} & \multirow[b]{2}{*}{$95 \% \mathrm{Cl}$} \\
\hline & Underweight & Normal weight & Overweight/obese & & \\
\hline \multicolumn{6}{|l|}{ Total $(n=499)$} \\
\hline$\%$ perceived child as underweight & 34.8 & 7.6 & 0 & & \\
\hline$\%$ of the total agreement & 1.6 & & & & \\
\hline$\%$ perceived child as normal weight & 65.2 & 90.2 & 61.6 & $0.352^{*}$ & $0.276-0.428$ \\
\hline$\%$ of the total agreement & & 57.3 & & $(71.1)$ & \\
\hline$\%$ perceived child as overweight/obese & 0 & 2.2 & 38.4 & & \\
\hline$\%$ of the total agreement & & & 12.2 & & \\
\hline \multicolumn{6}{|l|}{ Family income $(n=499)$} \\
\hline \multicolumn{6}{|l|}{ High family income $(n=302)$} \\
\hline$\%$ perceived child as underweight & 33.3 & 7.4 & 0 & & \\
\hline$\%$ of the total agreement & 1.0 & & & & \\
\hline$\%$ perceived child as normal weight & 66.7 & 89.9 & 59.0 & $0.366^{*}$ & $0.196-0.451$ \\
\hline$\%$ of the total agreement & & 56.0 & & $(71.2)$ & \\
\hline$\%$ perceived child as overweight/obese & 0 & 2.7 & 41.0 & & \\
\hline$\%$ of the total agreement & & & 14.2 & & \\
\hline \multicolumn{6}{|l|}{ Low family income $(n=197)$} \\
\hline$\%$ perceived child as underweight & 35.7 & 7.8 & 0 & & \\
\hline$\%$ of the total agreement & 2.5 & & & & \\
\hline$\%$ perceived child as normal weight & 64.3 & 90.7 & 66.7 & $0.324^{*}$ & $0.197-0.451$ \\
\hline$\%$ of the total agreement & & 59.4 & & $(71.0)$ & \\
\hline$\%$ perceived child as overweight/obese & 0 & 1.6 & 33.3 & & \\
\hline$\%$ of the total agreement & & & 9.1 & & \\
\hline \multicolumn{6}{|l|}{ Children gender $(n=499)$} \\
\hline \multicolumn{6}{|l|}{ Girls $(n=236)$} \\
\hline$\%$ perceived child as underweight & 28.6 & 4.9 & 0 & & \\
\hline$\%$ of the total agreement & 1.7 & & & & \\
\hline$\%$ perceived child as normal weight & 71.4 & 92.4 & 66.7 & $0.314^{*}$ & $0.204-0.424$ \\
\hline$\%$ of the total agreement & & 56.4 & & $(69.1)$ & \\
\hline$\%$ perceived child as overweight/obese & 0 & 2.8 & 33.3 & & \\
\hline$\%$ of the total agreement & & & 11.0 & & \\
\hline \multicolumn{6}{|l|}{ Boys $(n=263)$} \\
\hline$\%$ perceived child as underweight & 44.4 & 9.9 & 0 & & \\
\hline$\%$ of the total agreement & 1.5 & & & & \\
\hline$\%$ perceived child as normal weight & 55.6 & 88.4 & 56.8 & $0.390^{*}$ & $0.282-0.498$ \\
\hline$\%$ of the total agreement & & 58.2 & & $(73.0)$ & \\
\hline$\%$ perceived child as overweight/obese & 0 & 1.7 & 43.2 & & \\
\hline$\%$ of the total agreement & & & 13.3 & & \\
\hline
\end{tabular}

${ }^{*} P<0.001$.

$\mathrm{Cl}$, confidence intervals.

portion of $65.2 \%$ of underweight and $61.6 \%$ of overweight/ obese children were misclassified by their mothers.

Higher values of agreement were observed for boys, and for those in the higher family income (Table 2), in the overweight/ obese group, in the higher education level and the young mothers group (Table 3 ). For the majority of variables presented, the values of agreement were weak ( $k$ ranged from 0.257 to 0.486 ), but were statistically significant (Tables $2 \& 3$ ).

Table 4 presents the percentages of correct and incorrect mothers' classifications of the child's weight status, by child weight status.
Within the group of underweight children, a higher percentage of normal-weight mothers classified their child's weight status incorrectly $(P=0.002)$. Within the group of overweight/ obese children, a higher percentage of mothers with a high education level classified their child's weight status correctly $(P=0.042)$.

\section{Discussion}

The results of this study indicate a high rate of maternal misclassification of child weight status; $65.2 \%$ of underweight and 
Table 3. Percentages and Cohen's Kappa values of agreement between mother's perceptions of child weight status and objectively measured child weight status by mother's weight status, age and education level

\begin{tabular}{|c|c|c|c|c|c|}
\hline \multirow{2}{*}{$\begin{array}{l}\text { Maternal perception of child's } \\
\text { weight status }\end{array}$} & \multicolumn{3}{|c|}{ Child weight status } & \multirow{2}{*}{$\begin{array}{l}\text { Cohen's Kappa coefficient } \\
\text { (\% total agreement) }\end{array}$} & \multirow[b]{2}{*}{$95 \% \mathrm{Cl}$} \\
\hline & Underweight & Normal weight & Overweight/obese & & \\
\hline \multicolumn{6}{|l|}{ Mothers' weight status $(n=448)$} \\
\hline \multicolumn{6}{|l|}{ Normal weight $(n=259)$} \\
\hline$\%$ perceived child as underweight & 9.1 & 7.6 & 0 & & \\
\hline$\%$ of the total agreement & 0.4 & & & & \\
\hline$\%$ perceived child as normal weight & 90.9 & 89.7 & 63.5 & $0.291^{*}$ & $0.173-0.409$ \\
\hline$\%$ of the total agreement & & 64.1 & & $(73.4)$ & \\
\hline$\%$ perceived child as overweight/obese & 0 & 2.7 & 36.5 & & \\
\hline$\%$ of the total agreement & & & 8.9 & & \\
\hline \multicolumn{6}{|l|}{ Overweight/obese $(n=189)$} \\
\hline$\%$ perceived child as underweight & 85.7 & 7.4 & 0 & & \\
\hline$\%$ of the total agreement & 3.2 & & & & \\
\hline$\%$ perceived child as normal weight & 14.3 & 91.7 & 60.3 & $0.421^{*}$ & $0.303-0.539$ \\
\hline$\%$ of the total agreement & & 52.9 & & $(71.4)$ & \\
\hline$\%$ perceived child as overweight/obese & 0 & 0.9 & 39.7 & & \\
\hline$\%$ of the total agreement & & & 15.3 & & \\
\hline \multicolumn{6}{|l|}{ Mothers' age $(n=495)$} \\
\hline \multicolumn{6}{|l|}{$\leq 39$ years old $(n=283)$} \\
\hline$\%$ perceived child as underweight & 16.7 & 8.1 & 0 & & \\
\hline$\%$ of the total agreement & 0.7 & & & & \\
\hline$\%$ perceived child as normal weight & 83.3 & 89.8 & 55.3 & $0.379^{*}$ & $0.275-0.483$ \\
\hline$\%$ of the total agreement & & 59.0 & & $(73.1)$ & \\
\hline$\%$ perceived child as overweight/obese & 0 & 2.1 & 44.7 & & \\
\hline$\%$ of the total agreement & & & 13.4 & & \\
\hline \multicolumn{6}{|l|}{$\geq 40$ years old $(n=212)$} \\
\hline$\%$ perceived child as underweight & 54.5 & 7.0 & 0 & & \\
\hline$\%$ of the total agreement & 2.8 & & & & \\
\hline$\%$ perceived child as normal weight & 45.5 & 91.4 & 69.9 & $0.320^{*}$ & $0.206-0.434$ \\
\hline$\%$ of the total agreement & & 55.2 & & $(68.4)$ & \\
\hline$\%$ perceived child as overweight/obese & 0 & 1.6 & 30.1 & & \\
\hline$\%$ of the total agreement & & & 10.4 & & \\
\hline \multicolumn{6}{|l|}{ Mothers' education level $(n=489)$} \\
\hline \multicolumn{6}{|l|}{ Low education level $(n=279)$} \\
\hline$\%$ perceived child as underweight & 41.2 & 7.2 & 0 & & \\
\hline$\%$ of the total agreement & 2.5 & & & & \\
\hline$\%$ perceived child as normal weight & 58.8 & 91.0 & 63.0 & $0.358^{*}$ & $0.258-0.458$ \\
\hline$\%$ of the total agreement & & 54.9 & & $(69.8)$ & \\
\hline$\%$ perceived child as overweight/obese & 0 & 1.8 & 37.0 & & \\
\hline$\%$ of the total agreement & & & 12.4 & & \\
\hline \multicolumn{6}{|l|}{ Medium education level $(n=124)$} \\
\hline$\%$ perceived child as underweight & 33.3 & 7.8 & 0 & & \\
\hline$\%$ of the total agreement & 0.8 & & & & \\
\hline$\%$ perceived child as normal weight & 66.7 & 89.6 & 70.5 & $0.257^{*}$ & $0.108-0.406$ \\
\hline$\%$ of the total agreement & & 55.6 & & $(66.9)$ & \\
\hline$\%$ perceived child as overweight/obese & 0 & 2.6 & 29.5 & & \\
\hline$\%$ of the total agreement & & & 10.5 & & \\
\hline \multicolumn{6}{|l|}{ High education level $(n=90)$} \\
\hline$\%$ perceived child as underweight & 0 & 9.0 & 0 & & \\
\hline$\%$ of the total agreement & 0 & & & & \\
\hline$\%$ perceived child as normal weight & 100 & 88.1 & 38.1 & $0.486^{*}$ & $0.292-0.680$ \\
\hline$\%$ of the total agreement & & 65.6 & & $(80.0)$ & \\
\hline$\%$ perceived child as overweight/obese & 0 & 3.0 & 61.9 & & \\
\hline$\%$ of the total agreement & & & 14.4 & & \\
\hline
\end{tabular}

${ }^{*} P<0.001$

$\mathrm{Cl}$, confidence intervals. 


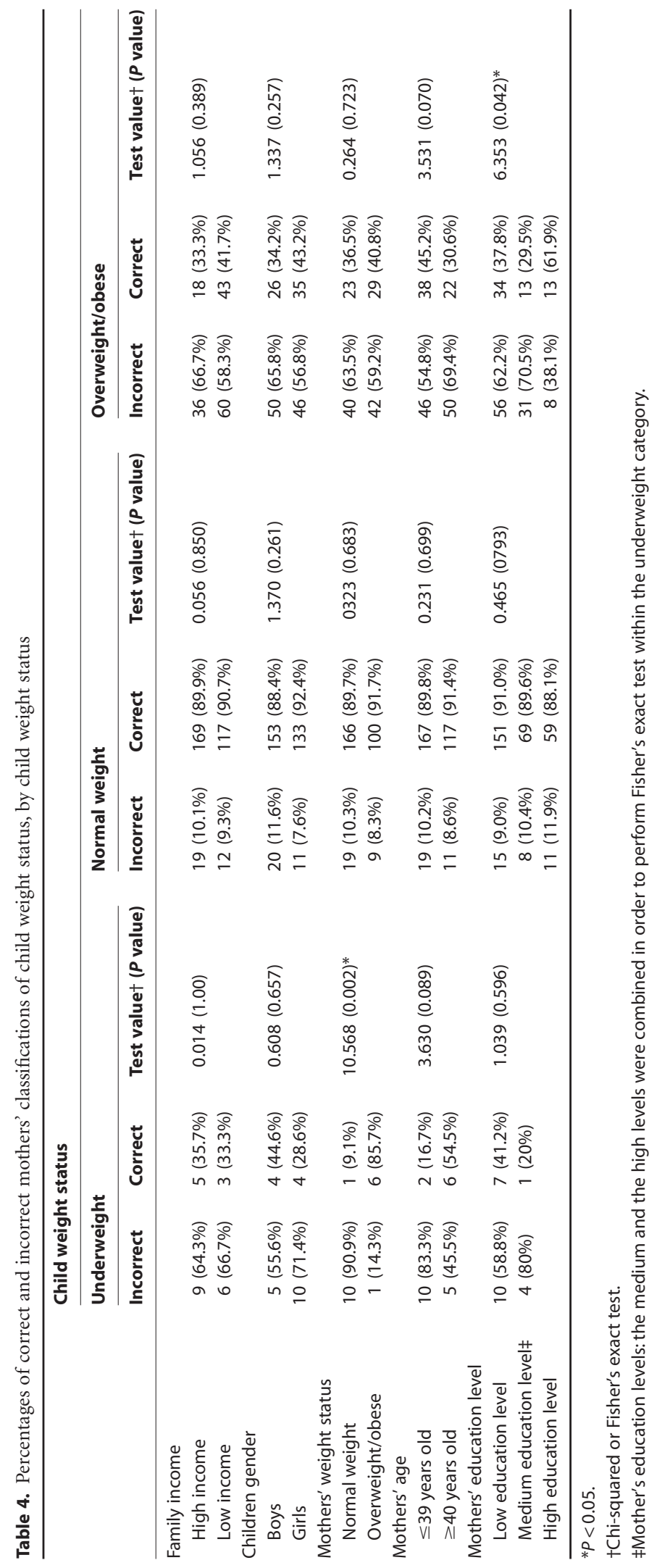


$61.6 \%$ of overweight/obese children were inaccurately classified by their mothers as being a normal weight. The agreement between the objectively measured weight status and the mothers' perceptions of their child's weight status was fair, but statistically significant. These findings are consistent with earlier studies that show that most parents do not correctly recognize their child's weight status (Baughcum et al. 2000; Wake et al. 2002; Maynard et al. 2003; Carnell et al. 2005; Jeffery et al. 2005; Campbell et al. 2006; Eckstein et al. 2006; West et al. 2008). Also, a recent review shows that in 19 of 23 studies reviewed, fewer than $50 \%$ of parents of overweight children recognize their child as overweight (Parry et al. 2008). This is a concern because the physical, social and emotional consequences of obesity may be evident in childhood and may persist into adult life (Dietz 1998).

Although these systematic misclassifications are not fully understood, they may be explained by a number of reasons and methodological limitations: (1) the increasing prevalence of overweight children may have 'normalized' this condition, leading to an increased acceptance of body fat and reduced ability of mothers to recognize when their own child has excess weight; (2) stereotypes of overweight children in media reports tend to show images of severe obesity, which could give a distorted impression of the criteria for being overweight (Campbell et al. 2006); (3) differences in sampling (clinical vs. epidemiological), i.e. clinical samples may be made up of participants whose parents already recognize in some part their weight problem while healthy participants also comprise epidemiological samples; (4) most of the studies have small sample sizes $(<100$ children), which preclude multivariable analyses (Campbell et al. 2006) and make the results less precise (Parry et al. 2008). Larger and more diverse samples might help identify other correlates and allow comparisons among studies; (5) there are no uniform or standardized tools for evaluating parental perceptions of weight status across studies (Towns \& D'Auria 2009); (6) children's weight status (and parental when it is the case) is calculated using different measurement instruments (questionnaires, interviews and objective and pictorial methods), and different standards are used to define childhood obesity (i.e. Centers for Disease Control and Prevention or International Obesity Taskforce cut-off points); (7) differences in the age range of the children studied. Some studies included children between 5 and 13 years old (Wake et al. 2002) and between 2 and 13 years old (Maynard et al. 2003) and compared what is incomparable because of their physical, psychological and social development differences; (8) socio-economic, cultural and social set differences. For example, Smith and colleagues (1999) observed cultural acceptance of larger body sizes among African Americans; (9) parents may want to avoid labelling because they fear it could stigmatize their child (Latner et al. 2005); (10) parents may avoid acknowledging their own weight status to avoid being blamed for their child's weight problem (Edmunds 2005); and (11) a lack of understanding of what overweight and obese mean (Maynard et al. 2003).

In the present study, $61.6 \%$ of overweight/obese children were classified by their mothers as being normal weight. These findings agree with West and colleagues (2008), indicating that the most common error is to underestimate the risk category, misclassifying overweight children as a normal or healthy weight (West et al. 2008). Our results highlight the need to educate parents about obesity and its health consequences in order to reduce misperceptions (Parry et al. 2008). Evidence suggests that parents who recognize their child's weight as a health problem are more likely to change their child's lifestyle habits (Rhee et al. 2005). Furthermore, a parental perception of a child being overweight is becoming a key variable in determining the family's readiness to modify the child's environment and lifestyle (Towns \& D’Auria 2009).

Despite higher values of agreement being observed for boys, high family income, and for overweight/obese, high education level and younger aged mothers, significant differences in the percentages of mothers who correctly classified their children's weight status were only found among the most educated in the overweight/obese group, and among the normal-weight mothers in the underweight group. This result is in line with Baughcum and colleagues (2000), who found that the misperceptions were more common in mothers with less education, while others (Maynard et al. 2003; West et al. 2008) found that socio-economic status did not influence parental perceptions. Indeed, education is positively associated with health-related knowledge (Tur et al. 2005) and with a higher capacity to put it into practice (Ball \& Crawford 2006).

Very little information is available on how parents perceive their underweight and normal-weight children. This study showed that $65.2 \%$ of underweight children are perceived as normal weight and $7.6 \%$ of normal-weight children are perceived as underweight. Although over-perception of thinness can lead to unhealthy dieting and eating disorders, underestimation on weight status can lead to overfeeding and may increase the risk of these children becoming overweight or obese. Consequently, it is important that parents have an accurate perception of their child's weight status.

Our findings have important public health implications, as the health-related behaviour (dietary practices, physical activity, sedentary behaviour) of school-aged children is mainly influenced and controlled by their parents (Lindsay et al. 2006). 
Inaccurate recognition and lack of parental concern may contribute to the persistence of unhealthy lifestyles (Wardle et al. 2006) and probably leads to less active attempts at the management and exacerbation of obesity (Lobstein et al. 2004). Even though the media and public health professionals are trying to increase awareness, these systematic misperceptions raise an important problem, because the general public awareness may not translate into an individual level of concern (Campbell et al. 2006).

This study extends the existing literature on parental weight perceptions by including data on Portuguese children, one of the countries with the highest prevalence of overweight and obese children in Europe, for the first time (Sardinha et al. 2011), and by presenting results of the mothers' perceptions of their child's weight status by BMI categories (underweight, normal weight, overweight/obese) according to the child's gender, the mother's age, education level and weight status and family income. Another strength of our study is the high response rate $(83.7 \%)$.

A limitation of this study is that the mothers' height and weight were self-reported and it is known that self-reported weight status underestimates the true prevalence of being overweight and obese, especially in women (Yun et al. 2006). Indeed, $58 \%$ of the mothers in our study were classified as normal weight, which is higher than the prevalence reported for Portuguese women (48.9\%) using objectively measured weight and height (do Carmo et al. 2008).

Future studies should investigate effective strategies for increasing a parent's awareness of their child's weight status.

\section{Conclusions}

Many mothers do not properly recognize their children's weight status and frequently underestimate their children's body size.

\section{Key messages}

- This study found that mothers do not properly recognize their children's weight status and frequently underestimate their children's body size.

- Significant differences in the percentages of mothers who correctly classified their children's weight status were only found among the most educated in the overweight/obese group and among the normal-weight mothers in the underweight group.

\section{Conflict of interest}

The authors declare no conflict of interest.

\section{Acknowledgements}

This work was supported by the Portuguese FCT-MCTES (BD/ 43808/2008 and BPD/65180/2009).

\section{References}

Altman, D. G. (1991) Practical Statistics for Medical Research. Chapman and Hall, London, UK.

Ball, K. \& Crawford, D. (2006) Socio-economic factors in obesity: a case of slim chance in a fat world? Asia Pacific Journal of Clinical Nutrition, 15 (Suppl.), 15-20.

Baughcum, A. E., Chamberlin, L. A., Deeks, C. M., Powers, S. W. \& Whitaker, R. C. (2000) Maternal perceptions of overweight preschool children. Pediatrics, 106, 1380-1386.

Campbell, M. W., Williams, J., Hampton, A. \& Wake, M. (2006) Maternal concern and perceptions of overweight in Australian preschool-aged children. Medical Journal of Australia, 184, 274-277.

do Carmo, I., Dos Santos, O., Camolas, J., Vieira, J., Carreira, M., Medina, L., Reis, L., Myatt, J. \& Galvao-Teles, A. (2008) Overweight and obesity in Portugal: national prevalence in 2003-2005. Obesity Reviews, 9, 11-19.

Carnell, S., Edwards, C., Croker, H., Boniface, D. \& Wardle, J. (2005) Parental perceptions of overweight in 3-5 y olds. International Journal of Obesity, 29, 353-355.

Cole, T. J., Bellizzi, M. C., Flegal, K. M. \& Dietz, W. H. (2000) Establishing a standard definition for child overweight and obesity worldwide: international survey. BMJ, 320, 1240-1243.

Cole, T. J., Flegal, K. M., Nicholls, D. \& Jackson, A. A. (2007) Body mass index cut offs to define thinness in children and adolescents: international survey. BMJ, 335, 194.

Dietz, W. H. (1998) Health consequences of obesity in youth: childhood predictors of adult disease. Pediatrics, 101 (Pt 2), 518-525.

Eckstein, K. C., Mikhail, L. M., Ariza, A. J., Thomson, J. S., Millard, S. C. \& Binns, H. J. (2006) Parents' perceptions of their child's weight and health. Pediatrics, 117, 681-690.

Edmunds, L. D. (2005) Parents' perceptions of health professionals' responses when seeking help for their overweight children. Family Practice, 22, 287-292.

Jeffery, A. N., Voss, L. D., Metcalf, B. S., Alba, S. \& Wilkin, T. J. (2005) Parents' awareness of overweight in themselves and their children: cross sectional study within a cohort (EarlyBird 21). BMJ, 330, 23-24.

Latner, J. D., Stunkard, A. J. \& Wilson, G. T. (2005) Stigmatized students: age, sex, and ethnicity effects in the stigmatization of obesity. Obesity Research, 13, 1226-1231. 
Lindsay, A. C., Sussner, K. M., Kim, J. \& Gortmaker, S. (2006) The role of parents in preventing childhood obesity. Future of Children, 16, 169-186.

Lobstein, T., Baur, L. \& Uauy, R. (2004) Obesity in children and young people: a crisis in public health. Obesity Reviews, 5 (Suppl. 1), 4-104.

Maynard, L. M., Galuska, D. A., Blanck, H. M. \& Serdula, M. K. (2003) Maternal perceptions of weight status of children. Pediatrics, 111 (Pt 2), 1226-1231.

Parry, L. L., Netuveli, G., Parry, J. \& Saxena, S. (2008) A systematic review of parental perception of overweight status in children. Journal of Ambulatory Care Management, 31, 253-268.

Portuguese Ministry of Education (2009) Family socioeconomic status. Available at: http://www.min-edu.pt/np3/4127.html (last accessed 10 October 2010).

Rhee, K. E., De Lago, C. W., Arscott-Mills, T., Mehta, S. D. \& Davis, R. K. (2005) Factors associated with parental readiness to make changes for overweight children. Pediatrics, 116, e94-e101.

Sardinha, L. B., Santos, R., Vale, S., Silva, A. M., Ferreira, J. P., Raimundo, A. M., Moreira, H., Baptista, F. \& Mota, J. (2011) Prevalence of overweight and obesity among Portuguese youth: a study in a representative sample of 10-18-year-old children and adolescents. International Journal of Pediatric Obsity, 6, e124-e128.

Smith, L. B., Thelen, E., Titzer, R. \& McLin, D. (1999) Knowing in the context of acting: the task dynamics of the A-not-B error. Psychological Review, 106, 235-260.
Towns, N. \& D’Auria, J. (2009) Parental perceptions of their child's overweight: an integrative review of the literature. Journal of Pediatric Nursing, 24, 115-130.

Tur, J. A., Serra-Majem, L., Romaguera, D. \& Pons, A. (2005) Profile of overweight and obese people in a Mediterranean region. Obesity Research, 13, 527-536.

Wake, M., Salmon, L., Waters, E., Wright, M. \& Hesketh, K. (2002) Parent-reported health status of overweight and obese Australian primary school children: a cross-sectional population survey. International Journal of Obesity and Related Metabolic Disorders, 26, 717-724.

Wardle, J., Haase, A. M. \& Steptoe, A. (2006) Body image and weight control in young adults: international comparisons in university students from 22 countries. International Journal of Obesity, 30, 644-651.

West, D. S., Raczynski, J. M., Phillips, M. M., Bursac, Z., Heath Gauss, C. \& Montgomery, B. E. (2008) Parental recognition of overweight in school-age children. Obesity (Silver Spring), 16, 630-636.

World Health Organization (2000) Obesity: Preventing and Managing the Global Epidemic. Technical Report Series No 894. In WHO (ed.). Geneve.

Yun, S., Zhu, B. P., Black, W. \& Brownson, R. C. (2006) A comparison of national estimates of obesity prevalence from the behavioral risk factor surveillance system and the National Health and Nutrition Examination Survey. International Journal of Obesity, 30, 164-170. 